\title{
Research on Building a Harmonious and Innovative City with High Efficiency
}

\author{
Yuping Zhang and Wenbin Liu * \\ Wuhan Technology and Business University, Wuhan,430065,China \\ (*Corresponding Author: Wenbin Liu, email:812926096@qq.com)
}

Keywords: Harmonious; Innovative; High efficiency

\begin{abstract}
City administrator is a high-frequency name in the news media, a web-click-sensitive noun, a career wandering between law and people livelihood. With the upgrading of urban grade, the intensity of scientific management will further increase, and the contradiction between people livelihood and rapid urban development will gradually emerge. How to build a harmonious and innovative and efficient city has been put in front of the theoretical researchers and urban management practitioners, so we have to seriously and deeply consider and study the subject.
\end{abstract}

\section{Introduction}

In recent years, city administrator is a high-frequency name in the news media, a web click sensitive term, a career between law and people livelihood.

In essence, urban management law enforcement should represent the image of the government. Whether it is Hubei Wuhan city administrator "flower law enforcement", to listen to persuade merchants to lay flowers, urban management members to carry out "undercover" task, "transposition thinking" in-depth understanding of the actual situation of traders, the " smile and law enforcement " in the city management team of Shuyang City, Jiangsu Province, or "the manager choke the woman vendor " of Guangzhou Chigang City Management in the process of Management, Shanxi Yan'an City administrator occur violent law enforcement, city administrator cause death of melon farmers in Linwu, Hunan Province. All of these more or less reflect that with the acceleration of urbanization construction in China, the requirement of socialized management is raised, especially the upgrading of urban management. Some people livelihood problems and contradictions gradually appear, which restrict the improvement of urban management level and the construction of harmonious urban management. With the problem of how to build a harmonious city management, I went to Xiangyang City, Wuhan City, You County, Shandong Changyi and other places to investigate and study. The results of the research on how to build a harmonious city management are as follows.

\section{The basic situation of Yicheng City Management}

\section{The Basic Situation}

The Yicheng Administration was established in March 2002 on the basis of the Urban Management Office of the former Municipal Government. The original intention of urban management was to solve the widespread problem of "seven big caps can not control one straw hat". According to Article 16 of the Administrative punishment Law of the people Republic of China, which came into effect on October 1, 1996, the Hubei Provincial Government approved in November 2007 to carry out the work of relatively centralized administration of administrative penalties in Yicheng, Yicheng Administrative Law Enforcement Bureau and City Administration Office, responsible for the city appearance management, environmental health management..

\section{The Basic Status}

Since 2015, especially after the construction of illegal construction in Yicheng has been carried out, that is, "harnessing the storm against the law", the work of urban management has focused on "efficient city administrator", "ruling by law" and "how to manage city administrator". With the full 
support of the Yicheng Municipal Party Committee and the municipal government, the framework and mechanism of Yicheng urban management system have been basically formed.

Firstly, Four specialized courses based on job responsibilities and management content.

The static traffic order management special class is responsible for the city planning area static vehicle parking investigation research, the planning establishment, the coordination instruction and the law investigation.

Outdoor advertising class is dedicated to urban street outdoor advertising planning, approval procedures, regular screening and late supervision.

The special class of public construction law enforcement is specially responsible for the investigation and treatment of illegal construction behavior in the enterprise construction market, the disposal of construction residue, and the management of civilized construction site.

The special class of building management in violation of rules and regulations is specially responsible for the control and investigation of private illegal and illegal construction of community residents.

The "four special classes" are administered vertically by the Urban Management Law Enforcement Bureau in the fields of personnel, property and funds, and law enforcement work is carried out in the field of urban management.

Secondly, City Management leading Group, Urban Management and Law Enforcement Bureau shall conduct business inspection and assessment on the appearance order, environmental hygiene, yard hygiene of 82 units of Yancheng office and the "four envelopes in front of the door" order without vertical leadership. The duties and responsibilities of the relevant functional departments is made clear, such as city building, transportation, food and drug supervision, industry and commerce, environmental protection, commerce, land, public security, traffic police, etc., and the whole city on inspection and examination is reported to. After more than a year of operation, a relatively scientific working mechanism has been preliminarily established, which basically adapts to the actual situation in our city. This kind of main body law enforcement, multilevel control, responsibility, power, benefit clear "big city management" pattern accords with our city management objective request and the development direction.

\section{Existing problems and causes}

With the acceleration of the pace of urban construction, the expansion of the urban scope, the construction of the village in the city, the transformation of the old urban area, the transformation of the old urban areas, the transformation of the peasants into the public, the transformation of the community from the village group to the community, the increasing population of the city, and the more and more requirements for the refinement and humanization of the urban management, the scientific and the standardization. Although it has been basically formed, "big city management" pattern still can not adapt to the rapid development of the city and the needs of rapid social change.

\section{"Great city administrator" pattern has not really been put in place}

Urban management is a systematic work, involving planning, transportation, land, construction, public security, industry and commerce, environmental protection, health, business and more than 20 departments, as well as municipal, street offices, community three levels. Although the document has clarified the division of duties and responsibilities among the various departments in urban management and the division of responsibilities among the three levels of responsibility, there is a lack of coordination and integrity in the actual management work. As the coordination of urban management functional departments, the Urban Urban Management and Law Enforcement Bureau has the relevant urban management functional departments and three levels. The authority of directing urban management functions will be reduced. It may lead to the failure of the various parts of the urban management system to play its proper functions. Then all kinds of problems and contradictions arising in this large system will focus on the urban management departments. And with the improvement of people material, cultural and living standards, the people pursuit of a better and more harmonious life is getting higher and higher.

The degree of meticulous management of city appearance environment is not enough 
There are universal phenomenons about mobile vendors occupy the road business, fixed shops out of the shop management, units to promote the road, and so on, in our old and new urban areas. In the early years of reform and opening up, in order to invigorate the economy and solve the problem of food and clothing, the operation of occupying the road business played a promoting role in economic development, and was once relatively prosperous. With the development of economy and the requirement of civilization of the times, the existence of occupying the road business operation directly affects the urban order, environmental hygiene and civilization, and restricts the development of urban modernization. That is to say, banning the operation of occupying the road business has become an important content of urban management in our city. At present, the management of mobile vendors in our city is under high pressure, It is not allowed to go out of the shop, the operation of occupying the road business or display the goods, regardless of any unit or individual.

\section{There are some problems in the construction of urban management team}

Although there have been great changes in the construction work of the urban management team in our city, and some achievements have been made, we are soberly aware that the value concept and value orientation of the urban management team have changed at present. There are some problems in team building, especially in human resource management.

First, the quality of personnel is uneven, the age structure problems are obvious. The city urban management law enforcement brigade is now a sub-section level unit, which is not included in the establishment of the full public enterprise. According to the statistics, the age structure of law enforcement players is over 40 years old, accounting for $71 \%$. Due to the limited allocation of staff funds, coupled with long working hours, urban management work has no sense of honor, it is difficult to recruit excellent management team members.

Second, training education lags behind. With the development of the city and the people pursuit of harmonious life, it is urgent for the urban management law enforcement personnel to strengthen the training and education. However, due to the busy nature of the city administrator work, the city administrator team members often work overtime and give up their rest. They are already physically and mentally exhausted, and the city administrator are used for their daily study, and the training time is short. At the same time, because of the weak cultural foundation, the difficulty of learning and the lack of funds, many of the urban management members did not reach the standard of learning and training.

Third, the incentive mechanism needs to be further improved. At present, urban management law enforcement has established performance appraisal measures and accountability mechanism, but the whole system has not yet formed a strong incentive mechanism.

Fourth, the citizens sense of urban management and the quality of civilization need to be further improved. The demands and expectations of many citizens on the level of urban management cannot be unified with the voluntary performance of their obligations. That is, the citizens hope that the urban management departments will increase the intensity of urban management, improve the management level. However, for the sake of their own interests, they will often build up, paste and draw indiscriminately, stop littering, throw away wastes, throw rubbish at random, and damaging municipal infrastructure. These are actions that damage civilized and harmonious cities.

\section{Countermeasure and Advice}

The construction of harmonious urban management is an important guarantee to consolidate the achievements of urban construction and make our city a city suitable for living, industry and innovation.

\section{Deepening the system of "Great Urban Management" is the need of harmonious development of our city}

The "big city management" system has been implemented in many cities of the country, and the effect is quite obvious. According to investigation, The "big city management" system has been in operation, and achieved good results in Wuhan and Xiangyang. To deepen urban management system in our city is to strengthen three points of authoritativeness, unity and coordination. 
"Great Urban Management" is the need of establishing activities and constructing innovative cities suitable for living in and suitable for business in our City. Deepening "urban management" system is not only the efficient operation of urban function, but also an effective way to construct harmonious urban management to promote the city image.

\section{Innovative evaluation method}

The first is to explore the way of professional evaluation. Under the premise that the evaluation standard, the evaluation project and the appraisal process remain unchanged, the evaluation method will be changed from the current non-specialization to the specialized evaluation, and the authority of inspection and evaluation will be further enhanced, and the rectification and rectification will be supervised. The second is to explore and implement the examination and evaluation of the third party. The third is to promote fine inspection and evaluation.

\section{Constructing the integration of urban and rural environmental health}

To realize the full coverage of urban and rural environmental sanitation is to bring the township, town appearance, village appearance and environmental sanitation into the unified planning and unified management. At the same time, we should actively promote the extension of sanitation resources, services and public facilities to towns, streets and villages.

Paying attention to hardware construction and promoting city fine management

Urban management facilities are the foundation. Focus on solving the hardware is not "hard", the status quo is not high grade, based on the functions of supporting cities, enhance the carrying capacity, create service-type "urban management", carefully build a harmonious city. The first is the construction of distribution in active investigation and analysis, overall layout, control of scale. The second is classified management in place.

The construction of a harmonious society puts forward higher requirements for the construction of the contingent in urban management work

The first is to establish an open mechanism for the supplement of urban administrators, and to increase the number of urban management law enforcement personnel appropriately. The second is to strengthen education and training. The third is to enhance the effectiveness and pertinence of the examination. The fourth is to have strict punishment mechanism, but also a mechanism of concern.

The construction of harmonious urban management can not be separated from the participation of all citizens

Urban management is facing more and more problems and challenges. Promoting citizen participation in urban management is an effective choice and an inevitable trend for the healthy and harmonious development of the city. The first is to rely on the carrier, diverse forms, rich citizens to participate in urban management activities. The second is to do a good job city management reports, complaints, set up the concept of service for the people. The third is to continuously strengthen education and publicity.

\section{Acknowledgements}

This research was supported by Special tasks of Humanities and Social Sciences Research of Hubei Provincial Department of Education in China (Grant No. 15Z159).

\section{References}

[1] Hong He, Chenglin Lu. Three problems of farmland circulation in the background of new urbanization[J]. Study and practice, 2015(4), pp. 32-38.

[2] Wei Peng. Transformation from "passive urbanization" to "active urbanization"[J]. Hubei Social Sciences, 2015(1), pp.75-79.

[3] Fangzhi Hu, Liang Li. Research on the process of people livelihood improvement in the process of urbanization[J]. Hubei Social Sciences, 2015(2), pp.82-87.

[4] Bin Lei. Strategic study on Xiangyang construction of the central city of the Hanjiang river basin[J]. Hubei Social Sciences, 2015(3), pp.58-63. 
[5] Zhongyi Tang, Fang Yuan. Prominent problems and countermeasures of urban management in Hubei province[J]. Hubei Social Sciences, 2015(4), pp.73-77.

[6] Zhao Chen. Study on the opening strategy of urban agglomeration in the middle reaches of Yangtze River [J]. Hubei Social Sciences, 2015(6), pp.57-62. 